\title{
Estado de Bem-Estar Social: Padrões e Crises*
}

JOSÉ LUÍS FIORI**

\section{RESUMO}

Este artigo recapitula brevemente a trajetória e os paradigmas históricos mais conhecidos de proteção social dos "excluídos" das sociedades capitalistas, para diferenciá-los do Welfare State contemporâneo, posterior ao Plano Beveridge. Logo em seguida contextualiza o sucesso da nova organização pública da proteção social, no âmbito da "Era de Ouro" do capitalismo, no período que vai de 1950 a 1970 . Para, depois de discutir algumas tipologias presentes na literatura sobre o Welfare, colocar o problema de sua lenta desarticulação ou redefinição no contexto das crises econômicas e da vitória ideológica do liberal-conservadorismo nos países centrais e periféricos.

Palavras-Chave: Estado de Bem-Estar; proteção social; crise.

\section{ABSTRACT}

\section{Welfare State: Patterns and Crisis}

This article recapitulates the most known trajectory and historical paradigms of social protection of the "excluded ones" in capitalist societies, differing from the present Welfare State, after the Beveridge Plan. Then it contextualizes the success of the new public organization of social protection, within the capitalist "Golden Age" (1950-1970). After discussing some typologies on the literature on Welfare, it places the problem of its slow inarticulation or

* Este texto faz parte da pesquisa apoiada pelo CNPq, "Globalização, Transição Hegemônica e Soberania".

** Cientista político, professor titular do Instituto de Economia Industrial da UFRJ e do Instituto de Medicina Social da UERJ. 
redefinition within the context of economic crises and the ideological victory of liberal-conservatism in central and peripheric countries.

Keywords: Welfare State; social protection; crisis.

\section{RÉSUMÉ}

\section{L'État Providence: Modèles et Crise}

Cet article est une recapitulation de la trajectoire et des paradigmes historiques plus connus de protection sociale des "exclus" des societés capitalistes, pour les différencier de l' État Providence contemporain, après le Plan Beveridge. Puis, l'article insére le succèss de la nouvelle organisation publique de protection sociale dans "l'Âge d'Or" du capitalisme, de 1950 à 1970. Après discutir quelques typologies de la litérature sur l'État Providence, on met le problème de sa lente désarticulation ou redéfinition dans le contexte des crises économiques et de la victoire idéologique du liberal-conservatisme aux pays centrales et périphériques.

Mots-clé: État Providence; protection sociale; crise. 
"Mais que ser dirigida às vítimas do mercado de trabalho e antes que os destinar a transformar o trabalho visto como mercadoria em trabalho visto como a base de um direito de cidadania industrial, o significado estratégico das políticas sociais passa a ser hoje o de uma arma para a modernização industrial competitiva". (Claus Offe, 1993)

\section{Conceitos e Histórias}

No campo das instituições, não há como recortar e definir "padrões" sem recorrer à História. Mas sem conceitos claros, a experiência histórica fica temporalmente indeterminada e acaba perdendo-se na multiplicidade infinita dos casos, impedindo a comparação entre seus processos e formas e inviabilizando, assim, a organização e a análise de suas tendências através da construção de tipos ou paradigmas. Uma premissa metodológica aparentemente simples, mas cuja imensa complexidade prática aparece de imediato quando tentamos reunir, sob um mesmo conceito - o da "proteção social" - instituições e práticas tão radicalmente distintas como são as Poor Laws e as Friendly Societies inglesas, os seguros sociais compulsórios alemães, dos tempos de Bismarck, as Caixas de Pensão brasileiras dos tempos de Eloy Chaves, o New Deal norte-americano de Roosevelt ou, finalmente, o Estado de Bem-Estar Social, a forma moderna mais avançada de exercício público da proteção social. E esta dificuldade cresce ainda mais quando constatamos que o próprio Welfare State que poderia servir de baliza ou referência "teleológica" para uma periodização e padronização das "formas inferiores" ou menos desenvolvidas de proteção social, apresenta uma variedade tão grande de trajetórias e formas no seu processo de construção e expansão, nos seus graus de profundidade e universalidade, e na sua maneira de enfrentar a crise e transição dos anos 80/90, que somos obrigados, de antemão, a reduzir as ambições analíticas deste artigo, focalizando apenas alguns aspectos do extenso debate que na literatura especializada cerca o universo sugerido pelo enunciado das questões que devo discutir.

Para isto, considero que o melhor caminho para começar a organizar o debate existente na literatura sobre o assunto é partir da resposta que os especialistas dão à pergunta sobre a existência ou não de uma descontinuidade essencial ou qualitativa que diferencie aquilo que se chama de Welfare State das várias formas de política social que lhe precederam historicamente. Formas de proteção que desde já há que se reconhecer, como um complicador do quadro, que ainda quando tenham sido inventadas, entre os 
séculos XV e XIX, reaparecem invariavelmente reapropriadas ou reaproveitadas de uma ou outra forma, em maior ou menor extensão, pelas várias organizações nacionais do welfare, posteriores à Segunda Guerra Mundial. Mas vamos por partes e comecemos pela questão conceitual. Aqui é possível distinguir três posições fundamentais: a primeira, com menor densidade teórica e maior preocupação historiográfica, privilegia a idéia de "proteção social", enquanto tal e isoladamente, e por isto tende a sublinhar a evolução mais do que as descontinuidades na trajetória que vai das Poor Laws, de 1536 a 1601, até o Plano Beveridge. A segunda posição, bem mais precisa no manejo conceitual, trabalha com a idéia de "políticas sociais", usa este conceito indiferenciadamente com o de welfare e vê uma nítida continuidade e evolução dessas políticas, pelo menos a partir da legislação securitária alemã. Inscrevem-se aqui tanto a visão clássica de Marshall (1964) sobre a evolução em três tempos — civil, política e social — da cidadania, quanto o estudo comparativo mais recente de Flora e Heidenheimer (1983), os quais localizam o início do welfare nos três últimos decênios do século XIX, fenômeno que associam com o nascimento da democracia de massas. Uma terceira posição que aparece defendida em escritos mais recentes (Esping-Andersen, 1990; Mishra, 1990, entre outros) sustenta, pelo contrário, a existência de uma ruptura qualitativa entre as políticas sociais anteriores à Segunda Guerra Mundial e o que veio a ser, a partir do Plano Beveridge, o welfare state contemporâneo.

A grande virtude dos estudos mais historiográficos foi a de identificar os padrões ou paradigmas originários do que poderíamos chamar de intervenção social do Estado na história da modernidade capitalista que se estende até o fim do século XIX: o inglês e o alemão. Com relação à Inglaterra, a investigação histórica permitiu identificar as estreitas relações nascidas entre a centralização do poder que acompanhou o nascimento dos Estados absolutistas e a "liberação" da força de trabalho camponesa que acompanhou a mercantilização das terras, e a proteção daí advinda, que foi dada aos pobres. Uma legislação preocupada explicitamente com a nova questão da ordem e do disciplinamento do trabalho, mas que deu lugar também a um tipo pioneiro de assistencialismo que não apenas se difundiu pela Europa, como se manteve presente como uma marca que atravessa a História inglesa, chegando até o Speenhamland Act, de 1796, e o Poor Law Act, de 1834. No plano legal, a dissolução das Poor Laws inglesas só ocorrerá em 1929.

Com relação à Alemanha, os historiadores souberam identificar a estreita associação entre a nova legislação bismarckiana e a repressão/antecipação 
ao movimento socialista, mas a pesquisa comparada sobre as políticas sociais soube identificar claramente a enorme diferença que separava o assistencialismo e as várias formas prévias de ajuda mútua do novo sistema securitário e compulsório que nasce nos anos 80 do século passado. $O$ que o distinguia era o fato de propor medidas e práticas permanentes; de assentar-se sobre um núcleo institucional diferenciado; de concentrar-se sobre trabalhadores masculinos e os obrigar à contribuição financeira compulsória e, finalmente, de institucionalizar procedimentos completamente diferentes dos que foram utilizados pelo assistencialismo prévio. Nascia ali um novo paradigma, conservador e corporativo, em que os direitos sociais, definidos de forma contratual, vinham outorgados "de cima" por um governo autoritário que ainda não reconhecera os direitos elementares da cidadania política. Este modelo generalizou-se pela Europa, como no caso do assistencialismo inglês, mas que acabou tendo, também, enorme influência na construção conservadora dos sistemas de assistência e proteção social que se multiplicaram na periferia latino-americana durante o século XX, mas sobretudo depois de 1930.

Não cabem dúvidas, entretanto, que só os estudos mais recentes (a segunda geração de estudos comparativos de que nos fala Esping-Andersen) propuseram um conceito capaz de dar conta da complexidade do fenômeno do welfare e, portanto, também de suas diferenças e descontinuidades fundamentais com as trajetórias e/ou padrões históricos anteriores, de organização das políticas sociais de tipo privado ou governamental, assistencial ou contratual. Para todos eles, o Plano Beveridge, ao legitimar o National Health Service Act, em 1946 criou um sistema nacional, universal e gratuito de assistência médica, financiado pelo orçamento fiscal, desvinculado, portanto, da relação contratual que havia caracterizado até então a essência das políticas sociais governamentais. Nascia ali, segundo esses autores, um novo paradigma e só ele poderia ser chamado corretamente de welfare. Segundo Esping-Andersen (1991) “o welfare state não pode ser compreendido apenas em termos de direitos e garantias. Também precisamos considerar de que forma as atividades estatais se entrelaçam com o papel do mercado e da família em termos de provisão social". Mishra (1990) talvez seja até mais radical: para ele não se pode falar em Estado de Bem-Estar Social antes de 1950. Mirsha associa o novo padrão ou paradigma a mudanças que ocorrem simultaneamente no plano da regulamentação da economia de mercado e à afirmação hegemônica das políticas econômicas ativas de inspiração keynesiana. Para ele não há como dissociar os serviços sociais universais, 
o objetivo de redistribuição e interação das rendas do objetivo maior do pleno emprego que norteou as políticas econômicas nacionais até os anos 80 . Claus Offe, em inúmeros trabalhos sobre o mesmo tema, agrega novas dimensões ao conceito e à prática do welfare, deixando clara sua inscrição como peça essencial de um contexto mais amplo que vigiu durante os trinta anos da chamada "era de ouro do capitalismo". Essas análises em conjunto permitem identificar pelo menos quatro grandes pilastras sobre as quais se assentaram a viabilidade e o sucesso dos welfare contemporâneos:

A primeira, constituída pelos fatores materiais ou econômicos que se manifestaram na forma (a) da generalização do paradigma fordista; (b) da existência de um consenso suprapartidário em torno aos valores do crescimento e do pleno emprego; (c) de um consenso paralelo em torno às políticas keynesianas; (d) da manutenção de um ritmo de crescimento econômico constante e sem precedentes na história capitalista; e (e) o que, por causa disto e por sua vez, permitiu ganhos fiscais crescentes que foram alocados por coalizões políticas socialmente orientadas, mesmo quando não fosse o caso de governos controlados diretamente pelos socialdemocratas.

A segunda, constituída pelo "ambiente" econômico global criado pelos acordos de Bretton Woods e que abria espaço para uma conciliação entre o desenvolvimento dos welfare e a estabilidade da economia internacional, o que Ruggie (1982) chamou de embedded liberalism. Nas palavras de Gilpin (1993, p. 33), "seguindo la teoria della política econômica, i governi avrebbero perseguito politiche macroeconomiche e di welfare allìnterno in maniera tale da non contrastare lê leffi ed erodere la stabilità del sistema econômico internazionale".

A terceira, constituída, inicialmente, pelo "clima" de solidariedade nacional que se instalou logo depois da Segunda Guerra dentro dos países vencedores e vencidos, e, logo depois, pela solidariedade supranacional gerada pelo novo quadro geopolítico. A nova situação, ao bipolarizar ideologicamente os conflitos mundiais entre duas propostas excludentes de organização econômica e social, criaram os estímulos ou receios necessários para consolidar as convicções "socialmente orientadas" de todos os governos, aí incluídos os conservadores, os democrata-cristãos e os liberais.

A quarta, constituída pelo avanço das democracias partidárias e de massa que, pelo menos nos países centrais - onde de fato pode-se falar de welfare -, permitiu que a concorrência eleitoral aumentasse o peso e a importância das reivindicações dos trabalhadores - e dos seus sindicatos e 
partidos - e dos demais setores sociais interessados no desenvolvimento dos sistemas de welfare states.

\section{Diáspora e Padrões}

Se a investigação mais recente permitiu - como sempre na hora em que a Coruja já levantou seu vôo - esclarecer melhor a complexa rede de determinações econômicas, ideológicas e políticas que definem e diferenciam o Estado de Bem-Estar Social contemporâneo dos sistemas anteriores de organização das políticas sociais governamentais, ela também explicitou melhor as diferenças que separam as várias experiências nacionais do mesmo welfare state. Já não cabe a menor dúvida, por exemplo, de que o modelo norteamericano tem muito pouco a ver com o modelo nórdico, e este com o da Europa continental, e de todos eles com o Japão. Para não falar de sua diferença com o welfare que foi sendo construído em algumas periferias capitalistas, em particular no caso latino-americano. Para dar conta desta nova dispersão, vários autores construíram, nestes últimos anos, tipologias que tentam aglutinar as várias experiências em alguns padrões básicos, diferenciados por sua forma de financiamento, pela extensão de seus serviços, pelo peso do setor público, pelo seu grau de sensibilidade aos sistemas políticos, pela sua forma de organização institucional etc. etc.

A mais antiga, e talvez a mais conhecida delas, foi sugerida por Titmus, já nos anos 60 e aparece sintetizada de forma crítica em Aureliano e Draibe (1989, p. 88):

"The residual welfare model of social policy", o padrão ou modelo residual, "onde a política social intervém ex-post e possui o caráter temporalmente limitado". Seria o caso contemporâneo dos Estados Unidos.

"The industrial achievement performance model of social policy", em geral traduzido como modelo ou padrão meritocrático-particularista, no qual a política social intervém apenas para corrigir a ação do mercado. "O sistema de welfare, nestes casos, é tão-somente complementar às instituições de mercado. A Alemanha talvez fosse, hoje, o caso que mais se aproxima deste modelo." Mais tarde, Ugo Ascoli (1984) tentou aumentar a precisão deste modelo, diferenciando dois subtipos seus: o "corporativo", no qual o peso dos sindicatos e corporações na delimitação e distribuição dos benefícios é maior do que no "clientelístico" onde o peso maior se desloca para o sistema partidário e se submete mais diretamente aos ciclos políticoeleitorais. 
"The redistributive model of social policy", ou padrão institucionalredistributivo, "voltado para a produção e distribuição de bens e serviços sociais 'extramercado' os quais são garantidos a todos os cidadãos universalmente cobertos e protegidos". Os países nórdicos, a Suécia em particular, seriam aqueles que mais se enquadrariam neste padrão.

Esping-Andersen também propõe uma tipologia para o que chamou de "regimes de welfare states", que ao fim e ao cabo não se distingue muito, no essencial, da que já havia sido proposta por Titmus. Também ele fala de três grandes grupos, ainda que destaque como seus critérios essenciais de diferenciação dos "regimes" a qualidade dos direitos sociais, o grau em que o sistema promove ou reproduz a estratificação social e a forma em que se relacionam, em cada um dos casos, o Estado, o mercado e as famílias:

$\mathrm{O}$ "welfare state liberal", "em que predominam a assistência aos comprovadamente pobres, reduzidas transferências universais ou planos modestos de previdência social e no qual as regras para habilitação aos benefícios são estritas e muitas vezes associadas ao estigma". São seus exemplos típicos: Estados Unidos, Canadá e Austrália;

Os "welfare states conservadores e fortemente corporativistas", nos quais "predomina a preservação das diferenças de status; os direitos, portanto, aparecem ligados à classe e aos status [...] e a ênfase estatal na manutenção das diferenças de status significa que seu impacto em termos de redistribuição é desprezível." Incluem-se aqui, como casos típicos, Áustria, França, Alemanha e Itália;

Os "regimes social-democratas", em que o universalismo e a desmercantilização atingem amplamente a classe média e "onde todos os segmentos sociais são incorporados a um sistema universal de seguros no qual todos são simultaneamente beneficiários, dependentes e, em princípio, pagadores". Não cabe dúvidas de que Esping-Andersen está falando aqui de um número limitadíssimo de países escandinavos.

Em nenhum caso a periferia capitalista, e latino-americana em particular, aparece considerada nessas tipologias. Depois do estudo clássico de Wanderley Guilherme dos Santos, Cidadania e Justiça (1979) sobre a configuração e a eficácia das políticas sociais brasileiras desenvolvidas sobretudo depois de 1930, só muito mais recentemente novos estudos comparativos (Aureliano e Draibe, 1989; Kornis, 1994; Soares, 1995, entre outros) têm permitido avançar na construção do que poderia vir a ser o padrão periférico de política social. Estes estudos têm acumulado preciosas informações sobre organização burocrático-institucional e sua articulação com os 
sistemas sindicais e político-partidários, assim como têm aportado novos e decisivos dados sobre volume de gastos, cobertura, formas de financiamento e gestão etc.

Como conclusão preliminar não ś difícil generalizar dizendo que todos estes novos estudos confirmam, de alguma maneira, a hipótese central de Santos:

"sugiro que o conceito-chave que permite entender a política social pós-30, assim como fazer a passagem da esfera da acumulação para a esfera da eqüidade, é o conceito de cidadania, implícito na prática política do governo revolucionário, e que tal conceito poderia ser descrito como o da cidadania regulada. Por cidadania regulada entendo o conceito de cidadania cujas raízes encontram-se, não em um código de valores políticos, mas em um sistema de estratificação ocupacional, e que, ademais, tal sistema de estratificação ocupacional é definido por norma legal. Em outras palavras são cidadãos todos aqueles membros da comunidade que se encontram localizados em qualquer uma das ocupações reconhecidas e definidas em lei" (Santos, 1979, p. 75).

Esta definição foi confirmada pelos estudos posteriores e situa o caso brasileiro muito próximo do tipo que Titmus chamou de "meritocráticoparticularista" e Esping-Andersen de "conservador e corporativista". De tal maneira que a discussão dos casos periféricos latino-americanos deve inevitavelmente deslocar-se para os matizes com que se combina em cada país o assistencialismo e as intervenções tópicas de tipo liberal com alguns sistemas universais de prestação de serviços de preservação ou mesmo complementação da renda.

Liana Aureliano e Sônia Draibe tentam detalhar com mais precisão o caso brasileiro e consideram que o sistema, pelo menos até suas reformas universalizantes dos anos 70/80, é basicamente "seletivo no plano dos beneficiários, heterogêneo no plano dos benefícios e fragmentado no plano institucional e financeiro". Mas consideram que as reformas posteriores do regime autoritário e tecnocrático que se instalou em 1964, acaba mudando a face do sistema de proteção ou welfare como preferem chamá-lo: "neste momento se organizam efetivamente os sistemas nacionais públicos ou estatalmente regulados, na área de bens e serviços sociais básicos, superando a forma fragmentada e socialmente seletiva anterior e abrindo espaço para certas tendências universalizantes". Mas, apesar disto, as autoras conside- 
ram que mesmo depois das reformas "o princípio do mérito constitui a base sobre a qual se ergue o sistema brasileiro de política social, além do que como a relação renda-contribuição-benefício segue dominante as políticas sociais, na sua maioria, reproduzem o sistema de desigualdades predominante na sociedade" (Aureliano e Draibe, 1989, p.143), aproximando-se fortemente do modelo meritocrático-particularista de Titmus, com aspectos tanto corporativos como clientelísticos, sobretudo pelo lado de um esquema de assistência extremamente denso e paralelo ao núcleo da seguridade. George Kornis, por fim, sintetiza em sua tese de doutoramento o que seriam os traços centrais do welfare brasileiro, não muito distante da maioria dos casos latino-americanos:

\begin{abstract}
"um financiamento regressivo do gasto social e uma hipertrofia burocrática que eleva em muito o custo operacional e favorece a manipulação clientelística. Um welfare state, em síntese meritocrático-particularista fundado na capacidade contributiva do trabalhador e num gasto público residual financiado por um sistema tributário regressivo. Um sistema nãoredistributivo e montado sobre um quadro de grandes desigualdades e de misérias absolutas [...]" (Komis, 1995, pp.58-59).
\end{abstract}

Talvez faltasse desenvolver um pouco mais, nesta linha de comparações e paralelismos, as condições em que se deram ou refrataram na América Latina, aquilo que chamamos antes de "grandes pilastras" do welfare nos países centrais durante os "vinte e cinco anos de ouro". Neste caso provavelmente deveríamos ter de explorar de uma forma em que não faremos aqui: 1) as diferenças materiais e econômicas entre as instituições e as políticas keynesianas e as suas congêneres desenvolvimentistas; 2) as distâncias entre os impactos diferentes que teveram a ordem política e econômica mundial sobre os países centrais, diretamente envolvidos na Segunda Guerra Mundial ou no seu desdobramento, a Guerra Fria; 3) e por fim, o papel que teve na atrofia de nossos welfare states, a predominância de regimes autoritários controlados por coalizões de poder extremamente reacionárias, predadoras e unidas internamente. Mas este é assunto para outro artigo.

\title{
Constituição e Expansão
}

A principal conclusão que se pode extrair deste tema entre os autores que defendem a especificidade estrutural das relações entre Estado, merca- 
do e política na configuração histórica do welfare state é de que não existe nem uma progressão linear, nem uma convergência inevitável entre os seus vários tipos nacionais, ou mesmo entre os seus vários padrões de construção e organização do Estado de Bem-Estar Social. É interessante notar, entretanto, que respeitadas as individualidades, quase todos os países, tipos e padrões seguiram uma evolução cujos grandes momentos e períodos são análogos porque estão determinados pela trajetória crítica do contexto mais amplo - econômico e político-ideológico de que já falamos - em que se ambientou o welfare. Mas, mesmo quando esta evolução obedece uma cronologia análoga, suas características e conseqüências têm sido diferentes em cada país, dependendo, é óbvio, das regras e formas que se consolidaram previamente.

Por isso a literatura especializada dedica uma atenção tão grande à identificação do que seriam os fatores ou "variáveis" que condicionaram ou determinaram as diferenças conhecidas na construção tanto quanto na expansão dos vários tipos de welfare. Aureliano e Draibe (1989) fizeram a melhor síntese que conheço do trabalho em que Jens Alber (1982) procurou consolidar um quadro das principais escolas teóricas - os pluralistas e os marxistas - e dos modelos com que procuram explicar a diáspora histórica das experiências de welfare: funcionalistas e conflitualistas. Em grandes linhas, para marxistas e pluralistas de tipo funcionalista, o welfare aparece historicamente como exigência da industrialização ou da acumulação do capital, para uns, seja da modernização e urbanização para os outros. Enquanto para funcionalistas e marxistas de tipo conflitualistas, o welfare aparece como resultado do avanço dos direitos dos cidadãos e da democracia, ou como produto da mobilização sindical e da luta política de classes. Sendo que no caso dos conflitualistas, este produto pode ainda haver aparecido historicamente "pelo alto" como obra de elites divididas ou fortemente pressionadas, ou ainda pode haver nascido "desde baixo", como resultado das pressões e da força política circunstancial da classe trabalhadora.

$\mathrm{Na}$ verdade, as variáveis e as hipóteses são tantas que suas combinações possíveis e admissíveis ficam quase infinitas. E o que se pode concluir com algum grau de consistência e consenso é que a maioria dos autores recorre, de uma forma ou outra, à variáveis ou fatores que se encontram dentro de alguma das seguintes grandes dimensões que estariam presentes em quase todas as explicações sobre a construção e expansão do Estado de BemEstar Social: 
- natureza, forma e ritmo do desenvolvimento econômico;

- grau, intensidade e organicidade da mobilização da classe operária;

- grau de avanço do desenvolvimento político-institucional;

- extensão ou impacto do efeito de difusão das inovações ocorridas nos países paradigmáticos;

- forma peculiar e a intensidade com que se desenvolve a luta política envolvendo os partidos que tradicionalmente representaram o mundo do trabalho.

Esping-Andersen, insatisfeito como tantos outros com a inconclusividade de todos estes modelos e a impotência de cada uma destas combinatórias de variáveis, propôs recentemente um modelo simplificador onde privilegia como "causas do regime dos welfare states", três ordens de fatores: "a natureza da mobilização de classe, principalmente da classe trabalhadora; as estruturas de coalizões políticas de classe e o legado histórica da institucionalização do regime" (Aureliano e Draibe, 1989, p. 111). E entre os três, ele não deixa de sublinhar a importância decisiva que teve em todos os casos históricos conhecidos o tipo de coalizão política que propôs e sustentou a construção e expansão do welfare, seja no caso da aliança "verde-vermelho" que comandou o processo sueco, seja no caso de sua variante norteamericana durante o período Roosevelt.

Neste nível de generalidade não é difícil estender o argumento e propor algumas hipóteses sobre a trajetória de expansão ou atrofia das políticas sociais na periferia latino-americana. Também ali a evolução das políticas sociais passou por etapas claramente demarcadas pela evolução do quadro político-econômico internacional e seus impactos reorganizadores das ordens políticas nacionais. De uma forma ou outra, os principais países do continente, incluindo os que já dispunham de legislação social avançada para a época, como era o caso do Uruguai e da Argentina, assistiram a uma inflexão que se seguiu à crise dos anos 30 , depois outra no pós-guerra, e mais outra nos anos em que as democracias foram sendo paulatinamente substituídas pelos regimes autoritários em quase todo o Continente. Sendo de destacar que no caso brasileiro, pelo menos, os dois grandes surtos de expansão dos sistemas de proteção social ocorreram durante regimes autoritários e sob o governo de coalizões conservadoras. $O$ primeiro, como já vimos, de natureza mais corporativista, e o segundo, mais universalista, ainda que acompanhado de traços fortemente clientelistas. Mas, deve-se reconhecer, também aqui, a falta de 
um estudo comparado mais aprofundado sobre as condições políticas em que se fizeram as opções básicas responsáveis pelas características - já comentadas - do nosso welfare periférico.

\section{Crise e Transição}

Exatamente em 1981 a OECD publicou um informe com um título emblemático para a época: "The Welfare State in Crisis". Nele diagnosticava de forma contundente:

"The rapid growth of social programmes in the 1950 and 1960s in $O E C D$ countries was closely related to high rates of economic growth and, thus, to the successful management of the OECD economies. The lower growth performance of the OECD economies since the early 1970 s was bound to disrupt the continuing extension of programmes and the growth of benefits - and in that sense the financial crisis of social security is closely related to high rates of unemployement not only because of the growing burden of unemployement compensation, but because unemployement has an impact on a wide range of social expenditures. Moreover, it begins to be argued that some social policies have negative effects on the economy, even to the extent of partly inhibiting the return to non-inflationary growth" (OCDE, 1981, p. 5).

Estavam aí repostos os termos de um debate que começara antes, nos anos 60/70, sobre a crise de governabilidade dos Estados pressionados, segundo os conservadores, por um excesso de demandas democráticas e por um Estado de Bem-Estar Social cada vez mais extenso, pesado e oneroso, o responsável central, segundo eles, pela própria crise econômica que avançou pelo mundo todo a partir de 1973/75.

$\mathrm{Na}$ verdade, as críticas precederam às crises. Não é o caso de recapitular aqui o que foi o nascimento teórico/ideológico da nova direita e da nova esquerda nos anos 60 . Vários foram os que já mapearam adequadamente os seus pontos de convergência crítica por detrás de suas enormes divergências propositivas. Mas, com relação ao tema de nosso interesse, neste artigo, cabe relembrar sucintamente que os novos conservadores viram no welfare state uma peça central no seu diagnóstico da crise dos Estados democráticos que já vinham formulando desde a segunda metade dos anos $60 . \mathrm{Na}$ mesma época em que a nova esquerda, em nome de um projeto de apro- 
fundamento da "democracia participativa" também viu no Estado de BemEstar Social uma peça central do imenso e anônimo aparelho de Estado responsável por um gigantesco trabalho de "cooptação" e desativação da classe trabalhadora.

Seja como for, a verdade é que as idéias neoconservadoras é que acabaram politicamente vitoriosas, difundindo-se de forma implacável por todo o mundo a partir de sua vitória no eixo anglo-saxão. E foram elas, portanto, que animaram os projetos neoliberais de reforma dos Estados que acabam atingindo em cheio os Estados de Bem-Estar Social, desacelerando sua expansão ou desativando muitos de seus programas. Depois de uma década e meia de hegemonia liberal-conservadora, entretanto, são muitos os autores que consideram que a destruição foi menor do que o que vem sendo apregoado.

Mas a verdade é que se a desmontagem dos welfare states não ocorreu de forma abrupta e estrondosa, são inúmeros os sinais que indicam uma lenta transformação ou transição de quase todos os casos ou tipos em direção às formas mais atenuadas ou menos inclusivas de cobertura dos vários sistemas que compuseram o welfare em seu período áureo. Lenta desativação que acompanhou os processos de ajuste macroeconômico e reestruturação industrial dos países centrais, e os processos de estabilização e desindustrialização dos países periféricos.

As reformas neoliberais adquiriram várias formas e matizes, mas alguns elementos estiveram presentes em todas elas: assim foi com a "remercantilização" da força de trabalho, a contenção ou desmontagem dos sindicatos, a desregulação dos mercados de trabalho e a privatização de muitos dos serviços sociais que estiveram previamente em mãos dos Estados. Reformas que se sucederam em tempos de enorme fragilização das forças políticas de esquerda e que acabaram promovendo cortes substantivos nos programas de integração de rendas, com redução simultânea dos demais programas de proteção social a níveis mínimos e preferentemente direcionados a públicos segmentados e específicos das populações mais pobres. Tudo feito com o objetivo declarado de encorajar a responsabilidade pessoal ou coletiva pela própria auto-assistência feita através do mercado. Como resultado, a tendência na maioria dos países tem sido a segmentação crescente dos esquemas de welfare, acompanhada de um maior papel dos grupos privados e de uma assinação de maior autonomia e poder aos setores voluntários e outros tipos de organizações privadas ou filantrópicas. 


\section{Dilemas e Cenários}

Hoje parece claro que da metade da década de 90 para cá de fato ocorreu uma confluência e sucessão de acontecimentos situados nos planos econômico, político e ideológico mundiais que acabaram abalando, de forma aparentemente definitiva, as bases em que se sustentavam as pilastras do welfare state dos anos 50/80, obrigando-o a alguma forma de reorganização, independentemente de quais sejam os seus governos. Refazer aqui a história desses acontecimentos é tão impossível quanto desnecessário. Basta entretanto recapitular os aspectos mais relevantes dessa transição mundial para comentar brevemente os seus impactos mais visíveis sobre o espaço nacional das políticas sociais neste final de século.

Mantendo a mesma ordem com que reconstruímos previamente a "ambientação" do embedded liberalism favorável à consolidação dos welfare states, há que se reconhecer hoje:

i) que no plano material ou econômico:

- o consenso que existe é rigorosamente contrário às idéias de crescimento e pleno emprego substituídas pelas idéias-força da estabilidade e dos equilíbrios macroeconômicos;

- as políticas keynesianas, por isto mesmo, estão em baixa e foram abandonadas por quase todos os governos, com exceção, talvez, dos Estados Unidos;

- o paradigma fordista é cada vez mais substituído pelas idéias de flexibilização e segmentação dos processos produtivos próprios a que vem se chamando de toyotismo;

- com raras exceções, o desemprego cresce no mundo inteiro e vem se alterando radicalmente o mix entre trabalho qualificado e desqualificado nos vários mercados nacionais;

- em quase todos os países se polarizam cada vez mais as relações entre mercados "primários" ou globalizados, e "secundários", fragmentando fortemente o mundo do trabalho e fragilizando invariavelmente o mundo dos sindicatos;

- por fim, o crescimento das economias se desacelerou de forma geral como resultado de políticas deflacionistas que acabam afetando a própria capacidade fiscal dos Estados.

ii) que no plano geopolítico

- o fim da Guerra Fria e a insolvência do socialismo real desfizeram as bases em que se sustentou, por medo ou por cálculo estratégico, 
a solidariedade entre os países centrais e de certa forma, ainda que em menor grau, destes com alguns países periféricos situados em zonas de importância estratégica;

- no seu lugar vêm surgindo, com força crescente, blocos regionais organizados em torno à supremacia econômico-monetária de três países que passam a competir entre si segundo as velhas regras que orientaram, desde sempre, a guerra entre os povos com "vocação" imperial;

iii) que no plano político-ideológico interno a cada país

- desapareceu o fantasma socialista;

- enfraqueceram-se os sindicatos e os partidos ligados ao mundo do trabalho;

- fragmentaram-se os interesses internos à classe trabalhadora;

- diminuiu enormemente a possibilidade de divergências no plano das políticas econômicas que possam afetar a credibilidade internacional dos governos e de suas economias candidatas aos investimentos dos capitais globalizados;

- em simultâneo com a diluição dos fatores de solidariedade nacional, o que se assiste é o avanço de forças desintegradoras sob o comando conservador e subserviente a um sistema de decisões que escapa completamente às instituições representativas próprias dos sistemas democráticos clássicos.

Devo sublinhar aqui o processo econômico da globalização como o epicentro material dessas transformações globais cujos impactos diretos sobre a viabilidade do welfare state podem ser sintetizados das seguintes maneiras:

(a) em primeiro lugar, as modificações da estrutura produtiva e ocupacional a que fiz referência acabam alterando a base socioeconômica do welfare na medida em que alteram a configuração e o fluxo dos riscos. Além, é claro, de aumentar as tensões sobre os equilíbrios financeiros dos sistemas, na medida em que diminuem o número dos contribuintes ao mesmo tempo em que aumentam as exigências no âmbito das prestações;

(b) em segundo lugar, as populações agora desocupadas de forma permanente se cruzam em vários espaços com o crescente movimento de imigração desencadeado pelas transformações econômicas e políticas, sobretudo na Europa do Leste;

(c) em terceiro lugar, a interdependência crescente, por opção ou imposição, ao condicionar de forma cada vez mais estreitas às gestões 
macroeconômicas nacionais, também acaba limitando os espaços autônomos de decisão dos governos no plano das políticas sociais. O caso europeu é ilustrativo, pois ali as decisões de Maastrich vêm impondo normas cada vez mais estritas com relação até ao nível de gastos e organização das políticas sociais;

(d) em quarto lugar, o fenômeno da competição global ou sistêmica, inaugurado pela desregulação dos mercados nacionais transformou os gastos com política social em custos que oneram a competitividade das empresas capazes de participar da competição global. Fenômeno que fechasse de maneira perversa e circular contra os próprios trabalhadores, que vêm sendo postos na disjuntiva de perder seus empregos ou abrir mão de seus sistemas de proteção;

(e) em quinto lugar, o fenômeno da polarização dos mercados de trabalho, mencionado anteriormente, vem expandindo o mundo dos "sem-classe" ou da "subclasse" que ficam cada vez mais excluídos dos mercados de trabalho e, como consequiência, de qualquer sistema de proteção, sobretudo porque aparecem cada vez mais corporativizados;

(f) em sexto lugar, e por fim, todos esses fatores conjugados não apenas diminuem a possibilidade de qualquer tipo de solidariedade interna (que não seja o de natureza étnica ou religiosa), como tornam cada vez mais problemática uma ação estatal que não seja vetada pelos seus altos custos do ponto de vista da competitividade sistêmica.

Com tudo isto fica extremamente difícil prever os horizontes possíveis ou cenários obrigatórios que se anunciam no fim desta mutação por que vêm passando todos os tipos e padrões de welfare construídos depois da Segunda Guerra Mundial. Talvez o que se possa afirmar com toda certeza é que existe um claro trade off entre as políticas e processos globalizantes e as políicas dos welfare states mais igualitários. Neste sentido, o sistema liberal americano deve ser o menos afetado pela globalização, enquanto os japoneses ainda não parecem ter claro se conseguirão resistir a pressões contrárias o sea sistema tradicional "empresarial-familiar" de proteção social. Entre os dois, os europeus são certamente os que mais perderão à medida que avancem as desregulações e as integrações dos mercados.

Por fim, como é sabido, esses mesmos processos, idéias e reformas chogr ram também, ainda que de forma tardia (com exceção do Chile) à priforia buino-americana. Nestes casos, os processos de reforma dos sis-ues de proteção social ainda estão em curso, mas não há como desconhece qu impacto sobre sistemas muito mais precários e sobre sociedades 
muito mais desiguais, deverá ser enorme. Ainda mais quando se tem presente que o próprio processo de reorganização da economia mundial afeta essas periferias de maneira a exponenciar seus traços anteriores mais perversos do ponto de vista social. Ali, as crises fiscais e financeiras dos Estados adquirem caráter crônico e vêm sendo enfrentadas pelo receituário neoliberal com a proposta pura e simples de cortes cada vez mais profundos no gasto público, sobretudo os de natureza social.

De maneira tal que é possível prever uma "transição" dos welfare states mais desenvolvidos para formas inferiores de atenção, situadas em algum ponto entre o modelo liberal norte-americano e o modelo corporativo alemão. No caso dos países periféricos, fica difícil imaginar que seja um cenário resultante da liberalização radical de sistemas que já eram basicamente de tipo liberal e assistencial, ainda quando contivessem "ilhas de universalidade".

\section{Referências Bibliográficas}

ALBER, J. Dalla carita allo stato sociale. Bologna: Il Mulino, 1986.

AURELIANO, L. e DRAIBE, S. (1989) A especificidade do welfare state brasileiro.

Economia e Desenvolvimento, n. 3, Brasîlia, MPAS e CEPAL, 1989.

ASCOLI, U. "II sistema italiano de Welfare". Welfare State allitaliana. Roma: Laterza, 1984.

ESPING-ANDERSEN, G. The three worlds of welfare capitalism. New Jersey:

Princeton University Press, 1990.

ESPING-ANDERSEN, G. As três economias políticas do Welfare State. Lua Nova, n. 24, setembro, 1991.

FLORA \& HEIDENHEIMER. Lo sviluppo del welfinstitucionalare state in Europa $e$ in America. Bologna: Il Mulino, 1983.

GILPIN, R. Welfare nazionale e norme economiche internazionali. In: FERRARA, M. (org.), Stato sociale e mercato. Torino: Edizione Fondazione Giovanni Agneli, 1993.

KORNIS, G. (1994), A Crise do Estado de Bem-Estar: Problemas e Perspectivas da Proteção Social. Tese de Doutoramento, IEI/UFRJ, 1994.

MARSHALL, T. H. "Class, Citizenship and Social Development". 1964.

MISHRA, R. The welfare sate in capitalist society: Policies of retrenchment and maintenance. In: Europe, North America and Australia, studies in international social policy and welfare. London: Harvester/Wheatsheaf, 1990.

OCDE. The Welfare in Crisis. Paris, 1981. 
OFFE, C. Politica sociale, solidarietà e stato nazionale. In: FERRARA, M. (org.), Stato sociale e mercato mondiale. Torino: Fondazione Giovanni Agnelli, 1993. RUGGIE, J.G. International regimes, transaction and change: Embedded liberalism in the postwar economic order. International Organization, v. XXXVI, 1982.

SANTOS, W. G. Cidadania e Justiça. Rio de Janeiro: Editora Campus, 1979.

SOARES, L. T. Ajuste neoliberal e desajuste social na América Latina. Tese de Doutoramento, Campinas, Instituto de Economia da Unicamp, 1995. TITMUS, R. Essays on the welfare state. London: Allen \& Unwin, 1963. 